Bergman: None declared, L. Guthrie: None declared, M. Alba: None declared, T. Pincus Shareholder of: Health Report Services, Inc DOI: 10.1136/annrheumdis-2017-eular.3500

\section{AB0233 REMISSION ACCORDING TO RAPID3 (ROUTINE ASSESSMENT OF PATIENT INDEX DATA 3) IN PATIENTS WITH RHEUMATOID ARTHRITIS: A CROSS-SECTIONAL STUDY FROM ROUTINE CARE AT 3 USA SITES}

I. Castrejon $^{1}$, M.J. Bergman ${ }^{2}$, K.A. Gibson ${ }^{3,4,5}$, Y. Yazici ${ }^{6}$, J.A. Block ${ }^{1}$,

T. Pincus ${ }^{1} .{ }^{1}$ Rheumatology, Rush University Medical Center, Chicago;

${ }^{2}$ Rheumatology, Taylor Hospital, Ridley Park, United States; ${ }^{3}$ Rheumatology,

Liverpool Hospital; ${ }^{4}$ Ingham Research Institute, Liverpool; ${ }^{5}$ University of NSW,

Sydney, Australia; ${ }^{6}$ Rheumatology, NYU Hospital for Joint Diseases, New York,

United States

Background: RAPID3 remission criteria provide similar results to DAS28 criteria, although less stringent compared to ACR/EULAR Boolean criteria. RAPID3 remission criteria are more feasible in routine care ${ }^{1}$ and have been reported at $25 \%$ in patients from France ${ }^{1}$ and $21 \%$ from Norway ${ }^{2}$

Objectives: We examined the proportion of patients in remission and 3 other severity categories according to RAPID3 at 3 sites at which MDHAQ is completed by all patients in routine care.

Methods: All patients seen at each rheumatology site complete an MD$\mathrm{HAQ}$ /RAPID3 at all visits in the waiting area as part of their routine care. The MDHAQ includes $0-10$ scores for physical function, pain and patient global estimate, compiled into a 0-30 RAPID3, as well as scores for fatigue, RADAI self-report of painful joints, and demographic data. Physicians complete a global assessment (DOCGL) on a 0-10 visual analog scale (VAS). A random visit with complete questionnaire data for each RA patient from each site was included in the analyses. The proportion of patients in 4 RAPID3 categories, high severity $(>12 / 30)$, moderate severity $(6.1-12)$, low severity $(3.1-6)$, and remission $(\leq 3)$, was computed. MDHAQ demographic and clinical measures and DOCGL were compared in the 4 RAPID3 severity groups using chi-square and ANOVA tests. Results: 420 RA patients from the 3 sites were analyzed. Remission rates according to RAPID3 severity ranged from $23 \%$ to $26 \%$, similar to reported rates from France and Norway. Low severity ranged from $7-24 \%$, moderate severity from $23-29 \%$ and high severity from $21-46 \%$. Age and sex were similar in the disease severity categories at the 3 sites (Table). Patients in the moderate and high severity groups at each site had higher scores for fatigue, RADAI self-reported joint pain, and DOCGL.

Table 1. Mean (SD) for demographic and clinical characteristic of patients in remission versus other disease severity categories according to RAPID3 in each site. ${ }^{*} p<0.001$

\begin{tabular}{lcccc}
\hline & Remission $(\leq 3)$ & Low $(3.1-6)$ & Moderate $(6.1-12)$ & High $(>12)$ \\
\hline Site 1 (N=137) & $32(23.4 \%)$ & $11(8 \%)$ & $31(22.6 \%)$ & $63(46 \%)$ \\
Female, n (\%) & $27(84.4 \%)$ & $9(81.8 \%)$ & $26(83.9 \%)$ & $59(93.6 \%)$ \\
Age, yrs & $58.5(16.9)$ & $57.9(18.8)$ & $56.8(17.5)$ & $55.6(14.5)$ \\
Fatigue (0-10) & $1.1(1.5)$ & $2.3(2.0)$ & $3.1(2.1)$ & $6.6(2.3)^{\star}$ \\
Self-report RADAI (0-48) & $1.9(2.9)$ & $5.0(3.9)$ & $7.5(5.60$ & $17.0(9.2)^{\star}$ \\
DOCGL (0-10) & $1.6(1.2)$ & $3.7(1.7)$ & $3.2(1.4)$ & $5.3(1.9)^{\star}$ \\
Site 2 (N=144) & $37(25.7 \%)$ & $35(24.3 \%)$ & $42(29.2 \%)$ & $30(20.8 \%)$ \\
Female, n (\%) & $28(75.7 \%)$ & $22(62.9 \%)$ & $34(80.9 \%)$ & $24(80 \%)$ \\
Age, yrs & $56.6(16.9)$ & $62.0(14.6)$ & $62.3(14.7)$ & $62.5(15.9)$ \\
Fatigue (0-10) & $0.9(1.0)$ & $2.7(1.9)$ & $4.1(2.4)$ & $5.6(3.0)^{\star}$ \\
Self-report RADAI (0-48) & $\mathrm{NA}$ & $\mathrm{NA}$ & $\mathrm{NA}$ & $\mathrm{NA}$ \\
DOCGL (0-10) & $0.9(1.3)$ & $1.0(1.0)$ & $1.7(1.5)$ & $3.4(2.7)^{\star}$ \\
Site 3 (N=139) & $32(23 \%)$ & $10(7 \%)$ & $33(23.7 \%)$ & $64(46 \%)$ \\
Female, n (\%) & $23(72 \%)$ & $9(90 \%)$ & $20(62 \%)$ & $50(79 \%)$ \\
Age, yrs & $44.4(13.8)$ & $43.8(17.0)$ & $50.3(17.8)$ & $50.9(15.0)$ \\
Fatigue (0-10) & $0.4(0.8)$ & $2.6(2.7)$ & $4.1(2.7)$ & $6.9(2.9)^{\star}$ \\
Self-report RADAI (0-48) & $1.3(1.9)$ & $4.7(4.2)$ & $5.7(5.1)$ & $18.3(12.2)^{\star}$ \\
DOCGL (0-10) & $1.1(1.1)$ & $3.2(1.9)$ & $2.5(1.2)$ & $3.2(1.5)^{\star}$ \\
\hline
\end{tabular}

Conclusions: Similar RAPID3 remission rates were seen at 3 USA sites (about $24 \%$ ), comparable to results from France and Norway.

References:

[1] Castrejon I, Dougados M, et al. J Rheumatol 2013, 40(4):386-393.

[2] Uhlig T, Lie E, et al. J Rheumatol 2016, 43(4):716-723.

Disclosure of Interest: I. Castrejon: None declared, M. Bergman: None declared, K. Gibson: None declared, Y. Yazici: None declared, J. Block: None declared, T.

Pincus Shareholder of: Health Report Services, Inc

DOI: 10.1136/annrheumdis-2017-eular.2749

\section{AB0234 ORAL CONTRACEPTIVES, MENOPAUSE AND RHEUMATOID} ARTHRITIS IN KOREAN WOMEN: A NATIONWIDE STUDY

\section{J.H. Jung, H.S. Jeong, J.-H. Kim, G.G. Song, S.J. Choi, Y.H. Seo. Internal}

Medicine, Korea University Medical Center, Seoul, Korea, Republic Of

Background: Rheumatoid arthritis (RA) is a chronic autoimmune inflammatory disease with a multifactorial etiology. Hormonal factors, ethnicity and their interaction may result in the development of RA.

Objectives: We investigated the effects of oral contraceptives (OCs) and menopause on RA in South Korea women using nationwide data.
Methods: Data were collected from the 2008-2012 Korea National Health and Nutrition Examination Surveys. A total of 17,890 eligible participants were included. As there were significant differences in baseline characteristics between the patients on OCs and those not taking OCs, we used propensity score-matching to adjust for such differences. We calculated the odds ratios (ORs) and 95\% confidence intervals ( $95 \% \mathrm{Cls}$ ) of OCs leading to RA development.

Results: The peak incidence of RA was between $50-59$ years old. The overall rate of OC usage was $16.5 \%$ and mean duration of OC using was $18.41 \pm 28.78$ (ranged from 0 to 360) months. Before propensity score-matching, using multivariable logistic regression adjusted for traditional risk factors, taking $\mathrm{OC}$ was a significantly associated with RA development (OR 1.18, 95\% Cl 1.18-1.19, $p<0.001)$. After propensity score-matching, taking OCs was not associated with RA (OR 1.05, $95 \% \mathrm{Cl} 0.83-1.34, p<0.001)$. Menopausal status showed strongly significant increase in the risk of RA.

Conclusions: There was an association between menopausal status and RA development in South Korean women. However, usage of OCs did not show significant effects on the development of RA.

References:

[1] Pikwer M, Bergstrom U, Nilsson JA, Jacobsson L, Berglund G, Turesson C. Breast feeding, but not use of oral contraceptives, is associated with a reduced risk of rheumatoid arthritis. Ann Rheum Dis 2009:68:526-30.

[2] Hazes JM, van Zeben D. Oral contraception and its possible protection against rheumatoid arthritis. Ann Rheum Dis 1991;50:72-4.

[3] Pullerits $\mathrm{R}$, d'Elia HF, Tarkowski A, Carlsten $\mathrm{H}$. The decrease of soluble RAGE levels in rheumatoid arthritis patients following hormone replacement therapy is associated with increased bone mineral density and diminished bone/cartilage turnover: a randomized controlled trial. Rheumatology (Oxford) 2009;48:785-90.

[4] Doran MF, Crowson CS, O'Fallon WM, Gabriel SE. The effect of oral contraceptives and estrogen replacement therapy on the risk of rheumatoid arthritis: a population based study. J Rheumatol 2004;31:207-13.

Disclosure of Interest: None declared

DOI: 10.1136/annrheumdis-2017-eular.4769

\section{AB0235 EFFECT OF BASELINE DISEASE ACTIVITY ON ACHIEVING SUSTAINED LOW DISEASE ACTIVITY IN BARICITINIB PHASE 3 STUDIES}

J.R. Curtis ${ }^{1}$, A. Kavanaugh ${ }^{2}$, D. van der Heijde ${ }^{3}$, D. Muram ${ }^{4}$, J. Alam ${ }^{4}$, J.S. Smolen ${ }^{5}$. ${ }^{1}$ Univ of Alabama at Birmingham, Birmingham; ${ }^{2}$ UC San Diego School of Medicine, la Jolla, United States; ${ }^{3}$ Leiden University Medical Centre, Leiden, Netherlands; ${ }^{4}$ Eli Lilly and Company, Indianapolis, United States; ${ }^{5}$ Medical University of Vienna, Vienna, Austria

Background: In the Phase 3 studies RA-BUILD ${ }^{1}$ and RA-BEAM ${ }^{2}$, baricitinib (bari) has demonstrated clinical efficacy including reduced disease activity in RA patients (pts) with an inadequate response (IR) to conventional synthetic DMARDs (csDMARDs)

Objectives: To determine whether disease activity at baseline $(B L)$ affects the achievement of sustained low disease activity (LDA) with bari treatment.

Methods: In this post hoc analysis, pts from the placebo (PBO) and bari $4 \mathrm{mg}$ treatment arms of the RA-BUILD and RA-BEAM studies were categorised based on their level of disease activity at BL; either CDAI $\leq$ median or CDAI > median, where median was 34.8 for RA-BUILD and 36.2 for RA-BEAM. Pts who achieved CDAl $\leq 10$ at $\geq 2$ consecutive visits (sustained LDA) within 12 and 24 weeks (wks) were considered as responders. The length of time required by pts to achieve sustained LDA was determined for each group using the incidence rate (percent pts responding per month). In addition, the association between response and dose of bari was explored in csDMARD-IR pts randomised to bari ( $2 \mathrm{mg}$ or $4 \mathrm{mg}$ ) once daily from the RA-BUILD study.

Results: Within the bari $4 \mathrm{mg}$ arm, a greater proportion of pts with CDAI $\leq$ median at $\mathrm{BL}$ achieved sustained LDA and within a shorter treatment duration as indicated by higher incidence rates, compared to pts with CDAI > median at BL. In pts with $\mathrm{CDAl} \leq 34.8$ at $\mathrm{BL}$, the $2 \mathrm{mg}$ and $4 \mathrm{mg}$ doses showed similar efficacy, but a larger proportion of pts with CDAI $>34.8$ reached sustained LDA at 24 wks with bari 4 $\mathrm{mg}$ than $2 \mathrm{mg}(41.4 \%$ and $32.4 \%$, respectively).

Table 1. Proportions and Rates of Sustained LDA Achievement with Baricitinib Treatment

\begin{tabular}{|c|c|c|c|c|c|c|c|}
\hline \multicolumn{2}{|c|}{ Pts achieving $\mathrm{CDAI} \leq 10$} & \multicolumn{3}{|c|}{$\mathrm{BL}$ CDAI $\leq$ median } & \multicolumn{3}{|c|}{ BL CDAI > median } \\
\hline & & PBO & Bari $4 \mathrm{mg}$ & Bari $2 \mathrm{mg}$ & PBO & Bari $4 \mathrm{mg}$ & Bari $2 \mathrm{mg}$ \\
\hline RA-BUILD & $\mathrm{N}$ & 116 & 108 & 114 & 108 & 116 & 111 \\
\hline \multirow[t]{2}{*}{ Wk12 } & $\%$ & 19.8 & 42.6 & 40.4 & 7.4 & 21.6 & 18.0 \\
\hline & i-rate & 4.36 & 11.78 & 10.50 & 1.55 & 4.69 & 3.90 \\
\hline \multirow[t]{2}{*}{ Wk24 } & $\%$ & 44.8 & 63.9 & 63.2 & 17.6 & 41.4 & 32.4 \\
\hline & i-rate & 10.63 & 19.20 & 17.59 & 3.80 & 9.59 & 7.27 \\
\hline RA-BEAM & $\mathrm{N}$ & 249 & 236 & & 235 & 246 & \\
\hline \multirow[t]{2}{*}{ Wk12 } & $\%$ & 23.7 & 39.8 & & 4.3 & 18.7 & \\
\hline & i-rate & 2.71 & 5.40 & & 0.42 & 1.98 & \\
\hline \multirow[t]{2}{*}{ Wk24 } & $\%$ & 34.5 & 69.1 & & 14.0 & 41.9 & \\
\hline & i-rate & 4.35 & 12.97 & & 1.49 & 5.47 & \\
\hline
\end{tabular}

Pts were defined as responders if they met the response criterion within the stated time frame prior to any rescue or discontinuation. $\%=$ percent of pts meeting response criteria; CDAI median $=34.8$ (RA-BUILD) or 36.2 (RA-BEAM); i-rate = exposure-adjusted incidence rate $(\% \mathrm{pts} / \mathrm{month}$ ); $\mathrm{N}=$ number of randomised and treated pts. 
Conclusions: Pts with CDAI $\leq 35-36$ at $\mathrm{BL}$ achieved sustained LDA more frequently and more rapidly than pts in the higher disease category at BL. In pts with higher disease activity at $\mathrm{BL}$ a more robust response was observed with bari $4 \mathrm{mg}$ treatment.

References:

[1] Dougados M et al. Ann Rheum Dis 2017; 76(1):88-95.

[2] Taylor P et al. Arthritis Rheumatol 2015; 67(Suppl 10):1-4046

Disclosure of Interest: J. Curtis Grant/research support from: AbbVie, Amgen, BMS, Corrona, Eli Lilly and Company, Janssen, Myriad, Pfizer, Roche/Genentech, UCB, Consultant for: AbbVie, Amgen, BMS, Corrona, Eli Lilly and Company, Janssen, Myriad, Pfizer, Roche/Genentech, UCB, A. Kavanaugh Consultant for: Eli Lilly and Company, D. van der Heijde Consultant for: AbbVie, Amgen, Astellas, Astra-Zeneca, BMS, Boeringer Ingelheim, Celgene, Daiichi Sankyo, Eli Lilly and Company, Galapagos, Gilead, Janssen, Merck, Novartis, Pfizer, Regeneron, Roche, Sanofi-Aventis, UCB, Employee of: Director of Imaging Rheumatology bv, D. Muram Employee of: Eli Lilly and Company, J. Alam Employee of: Eli Lilly and Company, J. Smolen Grant/research support from: Abbvie, Janssen, Eli Lilly and Company, MSD, Pfizer, Roche, Consultant for: Abbvie, Amgen, AstraZeneca, Astro, BMS, Celgene, Celltrion, Chugai, Gilead, Glaxo, ILTOO, Janssen, Eli Lilly and Company, Medimmune, MSD, Novartis-Sandoz, Pfizer, Roche, Samsung, Sanofi-Aventis, UCB, Speakers bureau: Abbvie, Amgen, Astra-Zeneca, Astro, BMS, Celgene, Celltrion, Chugai, Gilead, Glaxo, ILTOO, Janssen, Eli Lilly and Company, Medimmune, MSD, Novartis-Sandoz, Pfizer, Roche, Samsung, Sanofi-Aventis, UCB

DOI: 10.1136/annrheumdis-2017-eular.1340

\section{AB0236 ASSOCIATION OF LYVE-1 PROTEIN IN EXOSOME WITH DISEASE ACTIVITY AS A NEW CANDIDATE BIOMARKER FOR RHEUMATOID ARTHRITIS}

J. Yoo ${ }^{1}$, S.K. Lee ${ }^{2}$, M. Lim ${ }^{1}$, D. Sheen ${ }^{1}$, E.-H. Choi ${ }^{2}$, S.A. Kim ${ }^{1} .{ }^{1}$ School of Medicine; ${ }^{2}$ Eulji Medi-Bio Research Institute, Eulji University, Daejeon, Korea, Republic Of

Background: Exosomes, membrane-bound vesicles of $40-100 \mathrm{~nm}$ in diameter, have protein and lipid composition that depends on the cell origin, the state of activation, infection and/or transformation of the parent cells. Those proteins and lipid have a role in mediating inflammatory and autoimmune disease as well. Discovery of inflammatory marker to evaluate appropriate response of treatment could give effective timing to adjust treatment for rheumatoid arthritis patients.

Objectives: The aim of the study was to identify protein candidates in exosome being related with other inflammatory parameters.

Methods: The study population consisted of 60 RA patients, in which there were 30 patients of clinical remission (CR) group with DAS28-ESR $<2.6$ and 30 patients of non-clinical remission (non-CR) group with DAS28-ESR $>2.6$. By exosome preparation with ExoQuick ${ }^{\mathrm{TM}}$ kit and protein identification with tandem mass tags labeling/mass spectrometry between the groups, potent protein markers were selected. Level of the proteins was measured by ELISA.

Results: We identified 6 proteins by proteomics approach. Amyloid A (AA) and lymphatic vessel endothelial hyaluronic acid receptor-1 (LYVE-1) was identified with different levels in exosome between $\mathrm{CR}$ group and non-CR group. AA levels of both serum and exosome were higher in non-CR group than CR group ( $p$ value $=0.001$ ). Significant positive correlations were found between exosome AA level and CRP as well as between serum AA level and CRP $(\rho=0.614, p$ value $=0.001$ and $\rho=0.624, p$ value $=0.001$ ). Though $L Y V E-1$ level of serum was not different between non-CR group and CR group, LYVE-1 level of exosome was lower in non-CR group than CR group ( $p$ value $=0.01$ ). We found positive correlations between serum/exosome of LYVE-1 and CRP in only non-CR group (serum $\rho=0.376$, $p$ value $=0.04$; exosome $\rho=0.545$, $p$ value $=0.002$ ).

Conclusions: We suggest that LYVE-1 in exosome can be used as an additional marker of disease activity in RA patients and this study provides the evidence about the role of exosome for RA as the carrier of useful marker.

References:

[1] Mathivanan S, Ji H, Simpson RJ. Exosomes: extracellular organelles important in intercellular communication. J Proteomics. 2010 Sep;73(10):1907-20.

[2] Shen C, Sun X-G, Liu N, et al. Increased serum amyloid A and its association with autoantibodies, acute phase reactants and disease activity in patients with rheumatoid arthritis. Mol Med Rep. 2015;11(2):1528-34.

[3] Nunomiya K, Shibata Y, Abe S, et al. Relationship between serum level of lymphatic vessel endothelial hyaluronan receptor-1 and prognosis in patients with lung cancer. J Cancer. 2014;5(3):242-7.

Disclosure of Interest: None declared

DOI: 10.1136/annrheumdis-2017-eular.1194

\section{AB0237 PREVALENCE AND CLINICAL CHARACTERISTICS OF MALIGNANCY IN SEROPOSITIVE RHEUMATOID ARTHRITIS PATIENTS}

J. Park, C. Lee. Nhis Ilsan Hospital, Goyang, Korea, Republic Of

Background: Patients with rheumatoid arthritis (RA) are at an increased risk of malignancies compared with the general population.

Objectives: The aim of this study was to evaluate the prevalence and risk factors of malignancy in National Health Insurance Service Ilsan hospital patients with seropositive RA.

Methods: We found patients with seropositive RA who fulfilled the American College of Rheumatology criteria and American College of Rheumatology criteria/European League Against Rheumatism criteria, from May 2008 to September 2015. Occurrence of malignancy was originally collected by electronic medical record reports and diagnostic code. We consecutively enrolled patients with newly diagnosed malignancy. Control group was selected as five times the number of patients randomized.

Results: Total 12 malignancies in 647 patients were newly identified during the retrospective observation period of 2051 person-years. Malignancy types were 3 lung cancers, 2 colon cancers, gastric cancer, breast cancer, thyroid cancer, cervix cancer, cholangiocarcinoma, lymphoma and parotid gland cancer. In multivariate logistic regression, the variables with independent predictive value were older age (age: odds ratio $=1.11,95 \% \mathrm{Cl}=1.01-1.22, \mathrm{p}$-value $=0.02$ ), rheumatoid factor (RF) negativity (RF positivity: odds ratio $=0.06 .95 \% \mathrm{Cl}=0.01-1.27$, $p$-value 0.07 ) In cox regression, the variables with independent predictive value were older age (age: hazard ratio $=1.12,95 \% \mathrm{Cl}=1.01-1.24, \mathrm{p}$-value $=0.02$ ), negative $\mathrm{RF}$ (RF positivity: hazard ratio $=0.12 .95 \% \mathrm{Cl}=0.02-0.78$, p-value 0.02 ), lower anti-cyclic citrullinated peptide (CCP) antibody titer (anti-CCP antibody titer: hazard ratio $=0.98 .95 \% \mathrm{Cl}=0.96-0.99$, p-value 0.03 ) and positive antinuclear-antibody (ANA) (ANA positivity: hazard ratio $=14.97,95 \% \mathrm{Cl}=0.87-255.05$, p-value 0.06 ).

Table 1. Associations between variables and malignancy event in subjects: longitudinal data

\begin{tabular}{lcccccccc}
\hline Variables & \multicolumn{3}{c}{ Univariable } & & \multicolumn{3}{c}{ Multivariable } \\
\cline { 2 - 3 } & Hazard ratio & $95 \% \mathrm{Cl}$ & $\mathrm{p}$-value & & Hazard ratio & $95 \% \mathrm{Cl}$ & $\mathrm{p}$-value \\
\hline Etiology & & & & & & & & \\
$\quad$ Age & 1.14 & $1.05-1.24$ & $<0.01$ & & 1.12 & $1.01-1.24$ & 0.02 \\
$\quad$ Gender & 3.71 & $0.47-29.08$ & 0.21 & & & & \\
Laboratory results & & & & & & & \\
$\quad$ RF positivity & 0.33 & $0.09-1.13$ & 0.07 & & 0.12 & $0.02-0.78$ & 0.02 \\
$\quad$ Anti-CCP Ab titer & 0.99 & $0.98-1.00$ & 0.10 & & 0.98 & $0.96-0.99$ & 0.03 \\
$\quad$ ANA positivity & 5.56 & $0.69-44.64$ & 0.10 & & 14.97 & $0.87-255.05$ & 0.06 \\
\hline
\end{tabular}

Conclusions: Age, RF positivity, anti-CCP antibody titer, ANA positivity may be associated with malignancy risk in seropositive rheumatoid arthritis. So, continued vigilance and regular cancer screening are recommended for case of older age, RF negativity, lower anti-CCP antibody titer and ANA positivity.

Disclosure of Interest: None declared

DOI: 10.1136/annrheumdis-2017-eular.1587

\section{AB0238 THE INFLUENCE OF FATIGUE IN THE DEFINITION OF REMISSION IN RHEUMATOID ARTHRITIS PATIENTS TREATED WITH TOCILIZUMAB}

$\underline{\text { J. Caetano }}^{1}$, S. Oliveira ${ }^{1}$, J. Delgado Alves ${ }^{1,2} .{ }^{1}$ Systemic Autoimmune Diseases Unit, Department of Medicine IV, Fernando Fonseca Hospital, Amadora;

${ }^{2}$ CEDOC, NOVA Medical School, Lisbon, Portugal

Background: Achieving disease remission or low disease activity is the therapeutic goal in rheumatoid arthritis' (RA) treatment. Disease activity is defined through established criteria most of them requiring the evaluation of patient global assessment (PGA). PGA is considered a limiting factor for achieving remission definition, as it can be influenced by many factors not RA-related, namely fatigue which is commonly reported in RA and has been correlated with increased levels of interleukin-6 (IL-6).

Objectives: To evaluate the relation between PGA and fatigue, and whether fatigue influences disease remission definition in RA patients treated with tocilizumab (TCZ), an anti-IL-6 receptor monoclonal antibody.

Methods: We prospectively recruited 18 consecutive patients with RA (ACR/EULAR 2010 criteria), on TCZ treatment ( $>3$ months), from a single referral centre. Disease activity was evaluated by disease activity score for 28-joints (DAS28), and the ACR/EULAR Boolean-based criteria for remission were calculated. Visual Analog Scale for Fatigue (VASF) and Multidimensional Assessment of Fatigue scale (MAF) were used to measure fatigue.

Results: $89 \%$ of the patients were female and mean age was $55.5 \pm 13.8$ years (yrs). Mean disease duration was $8.8 \pm 6.8 \mathrm{yrs}$ and mean duration of TCZ treatment was $2.3 \pm 1.3 y r s(50 \% 1$ st line). Mean PGA score was $3.3 \pm 2.0$ (0-best health) and mean DAS28 C-reactive protein (CRP) was 2.27. According to DAS28-CRP 44\% of the patients were in remission, $22 \%$ had low disease activity and $33 \%$ had moderate activity. 3 patients (17\%) fullfield the ACR/EULAR Boolean criteria for remission. Considering all the composits of the Boolean criteria, PGA was the only reason for not achieving remission in 10 patients $(56 \%)$. The mean fatigue scores were: VASF 6.6 \pm 2.3 (0-best health), Global Fatigue Index (GFI), calculated through MAF scale, $24.3 \pm 14.9$ (1-best health). Amongst the 18 patients, PGA correlated with higher fatigue scores on VASF $(r=0.50, p=0.00951)$ and on GFI $(r=0.49, p=0.037)$. In the group of patients not fulfilling Boolean remission, a similar correlation between PGA and higher fatigues scores was found (VASF: $r=0.54, p=0.036$; GFI: $r=0.79, p=0.00041)$. In the sub-group of patients in which $\mathrm{PGA}$ was the only factor for not achieving Boolean remission, there was a significant correlation between PGA and fatigue scores ( $G F I: r=0.79, p=0.009$ ), that was not present in the other patients (GFI: $r=0.24 ; p=0.49$ ).

Conclusions: We found a positive correlation between higher PGA and fatigue 